\title{
MARRIAGE OF TWO COMPLETE ALBINOS WITH NORMALLY PIGMENTED OFFSPRING*
}

\author{
BY \\ P. D. TREVOR-ROPER \\ London
}

AlBINISM is a hereditary defect in melanin anabolism whose simple recessive inheritance appears to be undisputed (Duke-Elder, 1950; Sorsby, 1950; Waardenburg, 1932), so that defective children could be confidently anticipated should two albinos marry. The percentage of albinos in Scotland is about one in 21,000 and they are still rarer in England (Pearson and others, 1911), so that there is considerably less than one in a million chance of two such albinos marrying and the oculist has rare occasion to consider such a veto. Indeed, the only case on record is one among the 675 pedigrees tabled by Pearson and others (1911), and concerns two Fijian Islanders, long since dead, grandparents of an albino (also dead), who were recalled by a chief with a long memory; only two partial albino marriages (in Sierra Leone and the Phillipines) are noted, and subsequent pedigrees examined show no further case.

\section{Case Report}

Mr. and Mrs. I., both albinos, met at a partially-sighted school, married, and had three children with normal pigmentation and dark irides. There are no known albinoid relations, as shown in the accompanying pedigree (Fig. 1).

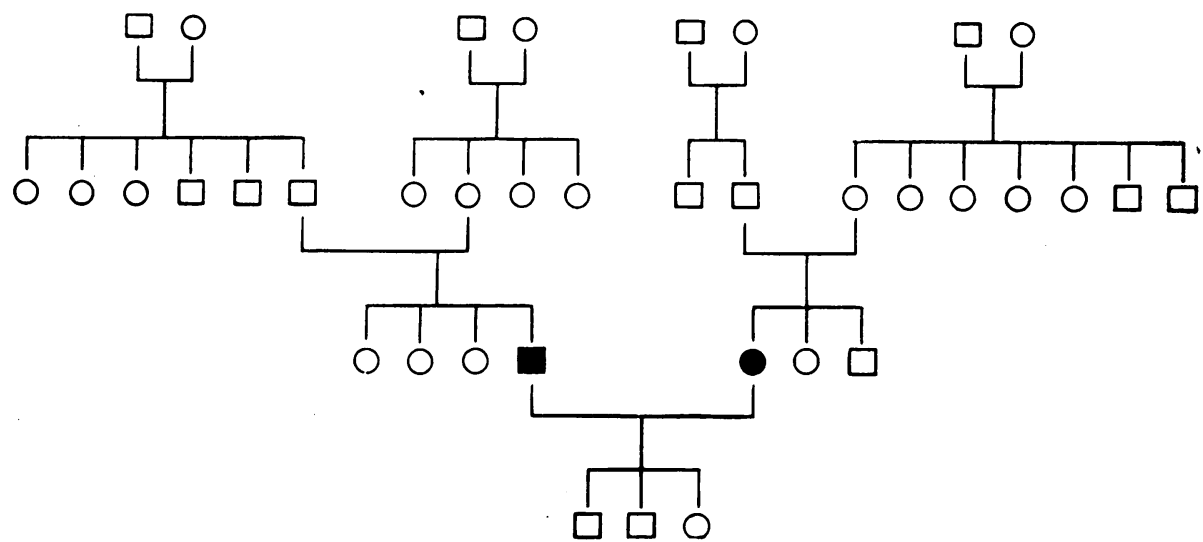

Fig. 1.-Pedigree of I. family.

* Received for publication November 12, 1951. 
Mr. F. I., aged 34, generalized albino, virtually complete, although hair slightly darker than his wife's, pink translucent irides, and albinotic fundi. Vision - Right 6/60 with $\frac{\varrho}{3}$ +1.5 D.S., 3 D.C., $90^{\circ}$; Left $4 / 60$ with 2 D.S., +3 D.C., 90' Alternatingo $50^{\circ}$ convergent squint with paresis of both external recti and marked rotatory nystagmus. $\vec{\Rightarrow}$

Mrs. J. V. I., aged 31, generalized albino, complete, pink translucent irides, and albinotic $\stackrel{5}{\stackrel{9}{9}}$ fundi. Vision - Right $-4 / 60$ with -12 D.S., -5 D.C. 180 ; Left $=3 / 60$ with -16 D.S. Alternating 20 divergent concomitant squint and marked rotatory nystagmus. $\frac{\sigma}{\bar{c}}$ Slight photophobia.

The first child died after a few hours but was certified by the doctor to be normally $\frac{\pi}{2}$ pigmented.

Fred I., aged 7, and Pamela I., aged 18 months, have normal pigmentation with dark brown irides (not translucent, as is said to occur in heterozygotes by Waardenburg), $\vec{\omega}$ normally pigmented fundi, and negligible refractive errors. The boy has vision $6 / 6$ in both $\stackrel{\circ}{\circ}$ eyes.

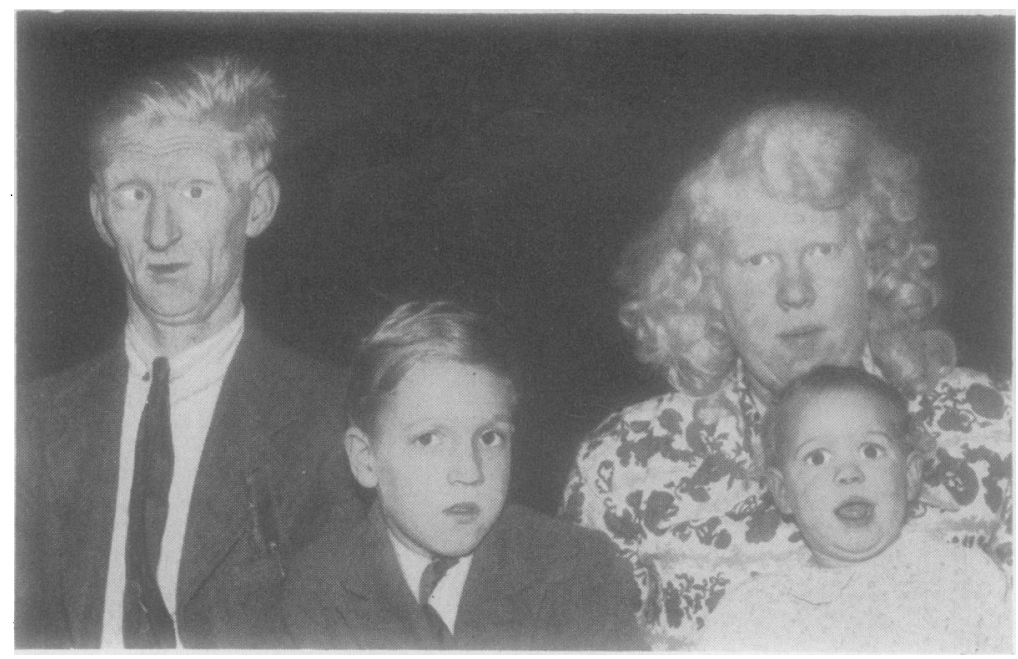

Fig. 2.-Four members of the I. family.

Although one case of apparent dominant inheritance among generalized albinos $\frac{\overline{0}}{0}$ in a Negro family (Pipkin and Pipkin, 1942) and two doubtful cases (Pipkin and Pipkin, 1942; Waardenburg, 1932) are quoted, such open violation of the Mendelian laws on three occasions deserves comment and perhaps also congratulations. The parents and their two surviving children are shown in Fig. 2.

My acknowledgements are due to Mr. A. G. Cross at whose clinic Mr. I. attended, and to the department of medical illustration at the Institute of Ophthalmology for the photographs.

\section{REFERENCES}

Duke-Elder, S. (1943). “Text-book of Ophthalmology”, vol. 2, p. 1398. Kimpton, N London.

Pearson, K.; Nettleship, E., and Usher, C. H. (1911). "A Monograph on Albinism in Man'. Biometric Series, London.

Pipkin, A. C., and Pipkin, S. B. (1942). J. Hered., 33, 419.

SORSBY, A. (1951). " Genetics in Ophthalmology". Butterworth, London. SORSBY, A. (1951). "Genetics in Ophthalmology". Butterworth, London.
WAardenBurg, P. J. (1932). "Das menschliche Auge und seine Erbanlagen". Nijhoff, The
Hague, Netherlands. 